\title{
Biomimetic electroactive polyimide with rose petal-like surface structure for anticorrosive coating application
}

\author{
W. F. Ji ${ }^{1}$, C. W. $L i^{1}$, S. K. Yu ${ }^{1}$, P. J. Chen ${ }^{1}$, H. L. Chen ${ }^{1}$, R. D. Chen ${ }^{2}$, B. H. Chen ${ }^{3}$, C. L. Hsu', J. M. Yeh ${ }^{1 *}$ \\ ${ }^{1}$ Department of Chemistry and Center for Nanotechnology, Chung-Yuan Christian University (CYCU), Chung Li, 32023 \\ Taiwan, Republic of China \\ ${ }^{2}$ Master Program in Nanotechnology, CYCU, Chung Li, 32023 Taiwan, Republic of China \\ ${ }^{3}$ Department of Cosmetic Application and Management, Far East University, Xinshi Dist., 74448 Taiwan, Republic of \\ China \\ ${ }^{4}$ Department of Physics, Chung-Yuan Christian University (CYCU), Chung Li, 32023 Taiwan, Republic of China
}

Received 18 December 2016; accepted in revised form 6 March 2017

\begin{abstract}
In this work, an electroactive polyimide (EPI) coating with biomimetic surface structure of rose petal used in anticorrosion application was first presented. First of all, amino-capped aniline trimer (ACAT) was synthesized by oxidative coupling reaction, followed by characterized through Fourier transform infrared spectroscooy (FTIR), liquid chromatography - mass spcerometry (LC-MS) and proton nuclear magnetic resonance $\left({ }^{1} \mathrm{H}-\mathrm{NMR}\right)$ spectroscopy. Subsequently, as-prepared ACAT was reacted with isopropylidenediphenoxy-bis(phthalic anhydride) (BPADA) to give electroactive poly(amic acid) (EPAA). Moreover, poly(dimethylsiloxane) (PDMS) was used to be the soft negative template for pattern transfer from the surface of rose petal to the surface of polymer coating. The EPI coating with biomimetic structure was obtained by programmed heating the EPAA slurry casting onto the negative PDMS template. The anticorrosive performance of as-prepared biomimetic EPI coating was demonstrated by performing a series of electrochemical measurements (Tafel, Nyquist, and Bode plots) upon cold-rolled steel (CRS) electrode in a $\mathrm{NaCl}$ aqueous solution. It should be noted that the biomimetic EPI coating with rose petal-like structure was found to exhibit better anticorrosion than that of EPI without biomimetic structure. Moreover, the surface contact angle of water droplets for biomimetic EPI coating was found to be $\sim 150^{\circ}$, which is significantly higher than that of EPI coating with smooth structure $\left(\sim 87^{\circ}\right)$, indicating that the EPI coating with biomimetic structure reveals better hydrophobicity.

The apparent mechanism for improved anticorrosive properties is twofold: (1) the biomimetic structure of EPI coating can repel water droplets. (2) electroactivity of EPI coating promotes the formation of densely passive layer of metal oxide on metallic surface.
\end{abstract}

Keywords: coatings, biomimetic, superhydrophobicity, electroactive polymer, corrosion

\section{Introduction}

Nature supplies inspiration for exploiting hierarchical structures to prepare biomimetic materials while focusing on environmental protection [1]. Due to multiplicity, abundance and renewability of natural resources different biological materials with unique geometries and internal structures can be used as templates and basic principles of organization assemblies, and alternative routes for fabricating new structures can be explored [2,3]. Scientists can synthesize a wide variety of materials inspired by biological species, such as bamboo [4], wood tattoo [5], seaweed [6], leaves [7-9], corn grains [10], peanut shells [11], sugar cane bagasse [12], cotton fibers [13], crab shells [14], butterfly wings [15], diatoms [16], egg shells [17], pollen grains [18], legumes [19], bacteria [20-22],

$\overline{{ }^{*} \text { Corresponding author, e-mail: juiming@,cycu.edu.tw }}$ (C) BME-PT 
viruses [23], cellulose [24-29], and DNA [30], with high reproducibility. Typically, these materials are often applied as uniform coatings with nanoscale or macroscale thicknesses. These practical examples have shown that biotemplates exhibit morphologically complex architectures, and promote an active site interaction between heterogeneous interfaces. In addition, they can be fabricated via the most common types of bottom-up fabrication procedures and are a means of creating useful three dimensional structures that may improve performance, particularly for anticorrosion applications.

For metal finish applications, corrosion control is always a concern and has therefore been a topic of extensive research. Currently, one of the standard industrial practices is to treat and/or coat metal surfaces with chromium-containing compounds. However, several adverse health and environmental effects of chromium compounds have been reported [31,32]. Many organic and/or polymeric coatings are designed to protect a metal from in-service corrosion. In the past decades, the use of electroactive polymers, such as polyaniline, as corrosion protection coatings was explored for the potential replacements of chromium-containing materials [33]. In addition, aniline oligomer-based electroactive polymers (such as polyimides [34], epoxy resins [35], and polyurethanes [36]) have also been applied as the anticorrosion coatings.

Recently, polymeric coatings with biomimetic surface structures have been examined as anticorrosion coatings. For example, Weng et al. [8] reported on an electroactive thermally cured epoxy coating with biomimetic Xanthosoma sagittifolium leaf-like structure; this coating fabricated via a nanocasting technique was found to exhibit long-term corrosion protection, even in strongly acidic aqueous solutions. Moreover, corrosion protection was also evident when biomimetic structure natural leaves were fabricated using room temperature-cured epoxy [37], and UV-cured polyacrylate coatings [38]. However, the fabrication of biomimetic surface structure base on natural rose petal upon coating has not been investigated as a means for producing anticorrosion coatings.

In this work, an electroactive coating with rose petallike surface structure is fabricated and evaluated for anticorrosion applications. First, amine-capped aniline trimer (ACAT) is synthesized by oxidative coupling, and then characterized by ${ }^{1} \mathrm{H}-\mathrm{NMR}$ and FTIR spectroscopies and liquid chromatography (LC)-mass spectrometry. Next, as-prepared ACAT is further reacted with 4,4'-(4,4-isopropylidenediphenoxy) bis (phthalic anhydride) (BPADA) in $N, N^{\prime}$-dimethylacetamide (DMAc) solution to give electroactive poly (amic acid) (EPAA). A soft negative PDMS template was then prepared via nanocating for pattern transfer with natural rose petal as the template. Finally, the biomimetic electroactive polyimide (EPI) coating was realized when the EPAA slurry was cast onto the negative PDMS template. Scanning electron microscopy (SEM) and atom force microscopy (AFM) are utilized to observe the surface topography with hierarchical structures of the biomimetic rose petal-like coatings. Superhydrophobicity and electroactivity of coatings with a rose petal-like surface structure are investigated on the basis of the static contact angle and electrochemical cyclic voltammetry, respectively. Standard electrochemical corrosion measurements are used to evaluate the biomimetic electroactive coating in $\mathrm{NaCl}$ solution. Moreover, electrochemical impedance spectroscopy (EIS) is employed to further confirm the enhanced corrosion protection of the coating with the rose petal-like surface.

\section{Experimental sections}

\subsection{Materials and measurements}

Aniline (Sigma-Aldrich) was distilled prior to use. The compounds 4,4-Diaminodiphenylamine sulfate, 4,4'-(4,4-isopropylidenediphenoxy) bis(phthalic anhydride) (BPADA, 97\%) and sodium chloride were purchased from Sigma Aldrich, while $N, N^{\prime}$-dimethylacetamide (DMAc) was purchased from Avantor. The liquid components (used for the soft template, Sylgard 184 and PDMS) were supplied by Dow Corning Corporation. All reagents were reagent grade unless otherwise stated.

Mass spectra were recorded on a Bruker Daltonics IT mass spectrometer model Esquire 2000 (Leipzig, Germany) with an Agilent ESI source (model G16076001). A Bruker 300 spectrometer, was used for measuring ${ }^{1} \mathrm{H}-\mathrm{NMR}$ spectra, and was referenced to an internal standard of tetramethylsilane (TMS). The solvent was dimethyl sulfoxide (DMSO- $d_{6}$ ). Attenuated total reflectance FTIR spectra were obtained at a resolution of $4.0 \mathrm{~cm}^{-1}$ and a range of 4000 to $650 \mathrm{~cm}^{-1}$ with a spectrometer (FT/IR-4200) at room temperature. Surface morphologies were observed by SEM, (JOEL JSM-7600F). Three-dimensional surface was characterized by AFM, (Park systems XE-100). Contact angles of water droplets at various positions on 
the sample surfaces were measured using a First Ten Angstroms FTA 125 goniometer at ambient temperature and the average contact angles from five measurements each position were calculated. Redox properties of as-prepared EPI coatings were investigated by cyclic voltammetry. Electrochemical corrosion measurements of sample-coated cold-rolled steel (CRS) electrodes were obtained by using VoltaLab 50 (PST050) potentiostat/galvanostat electrochemical analyzer. Electrochemical impedance spectroscopy (EIS) was performed using an AutoLab (PGSTAT302N) potentiostat/galvanostat electrochemical analyzer.

\subsection{Synthesis of amine-capped aniline trimer (ACAT)}

4,-4'-diaminodiphenylamine sulfate $(4.73 \mathrm{~g}$, $0.016 \mathrm{~mol})$ and aniline $(1.48 \mathrm{~g}, 0.016 \mathrm{~mol})$ were dissolved in a $\mathrm{HCl}$ aqueous solution $(1.0 \mathrm{~N}, 150 \mathrm{~mL})$ containing $15 \mathrm{~g}$ of $\mathrm{NaCl}$. A solution of ammonium persulfate $(3.6 \mathrm{~g}, 0.016 \mathrm{~mol})$ in $\mathrm{HCl}$ aqueous solution $(1.0 \mathrm{~N}, 25 \mathrm{~mL})$ was added at a rate of approximately $60 \mathrm{drops} / \mathrm{min}$ to the previously described solution at $5{ }^{\circ} \mathrm{C}$ using a dropping funnel. The reaction mixture was stirred for $1 \mathrm{~h}$ at $5^{\circ} \mathrm{C}$. The resulting precipitate was collected by filtration, followed by washing with large amounts of $\mathrm{HCl}$ aqueous solution $(1.0 \mathrm{~N}, 400 \mathrm{~mL})$. Then, the filtrate was washed with $\mathrm{NH}_{4} \mathrm{OH}$ solution $(1.0 \mathrm{~N}, 100 \mathrm{~mL})$ and followed by washing with distilled water. Thus, a blue powder was further dried in a vacuum oven at $50^{\circ} \mathrm{C}$ for $24 \mathrm{~h}$. The collected ACAT was a blue solid and the yield was approximately $40 \%$.

\subsection{Preparation of PDMS template}

The PDMS template was prepared by using a 10:1 mixture (by weight) of the base and curing agent. After thoroughly mixing the base and curing agent, the pre-polymer was poured onto the template of fresh rose petals and then subjected to program heating at $60^{\circ} \mathrm{C}$ for $2 \mathrm{~h}$ to ensure completion of the PDMS cross-linking process. Thus, a negative PDMS template was obtained.

\subsection{Synthesis of polyimide}

BPADA $(0.52 \mathrm{~g}, 1 \mathrm{mmol})$ was added to $5.0 \mathrm{~g}$ of DMAc at room temperature with continuous stirring for $30 \mathrm{~min}$. A solution containing 4,4'-Oxydianiline (ODA) $(0.20 \mathrm{~g}, 1 \mathrm{mmol})$ in another $5 \mathrm{~g}$ of DMAc was prepared under magnetic stirring. After stirring the ODA solution for $30 \mathrm{~min}$, ODA solution was mixed with BPADA solution at room temperature to produce PAA. The curing at $150^{\circ} \mathrm{C}$ was necessary to complete the imidization reaction from PAA to PI for $4 \mathrm{~h}$. PI was also prepared for control experiment and all PI-coated CRS electrode was used as working electrode in electrochemical corrosion measurements.

\subsection{Synthesis of electroactive polyimide (EPI)} BPADA $(0.52 \mathrm{~g}, 1 \mathrm{mmol})$ was added to $5.0 \mathrm{~g}$ of DMAc at room temperature with continuous stirring for $30 \mathrm{~min}$. A solution containing ACAT $(0.288 \mathrm{~g}$, $1 \mathrm{mmol}$ ) in another $5 \mathrm{~g}$ of DMAc was prepared under magnetic stirring. BPADA solution was added to the ACAT solution and stirring was continued for $3 \mathrm{~h}$ at room temperature to produce electroactive (polyamic acid) (EPAA). The EPAA was then coated onto the cold-rolled steel (CRS) substrate with and without the PDMS template, followed by curing at operational programmed temperature of $80^{\circ} \mathrm{C}$ for $1 \mathrm{~h}$. Another $4 \mathrm{~h}$ of curing at $150^{\circ} \mathrm{C}$ was necessary to complete the imidization reaction from EPAA to EPI. Both EPIcoated CRS electrode with and without rose petallike surface structures were used as working electrodes in electrochemical corrosion measurements.

\subsection{Electrochemical corrosion studies}

Coatings with $\sim 30 \mu \mathrm{m}$ thickness were obtained after drying in a fume hood for $24 \mathrm{~h}$ at room temperature. The edges of coupons were sealed with epoxy cement $\left(\operatorname{SPAR}^{\circledR}\right)$. The coated and uncoated coupons were connected to the working electrode of an electrochemical cell. For anticorrosion data, polarization curves were obtained by cyclic voltammetry (VoltaLab50 potentiostat/galvanostat) at a constant temperature. A 3.5\% $\mathrm{NaCl}$ aqueous solution was used as the electrolyte, and the three-electrode configuration was employed in the circuit with the sample as the working electrode, a graphite rod as the counter electrode, and saturated calomel electrode (SCE) as the reference electrode. The open circuit potential (OCP) at the equilibrium state of system was used as the corrosion potential $E_{\text {corr }}[\mathrm{mV}]$. For the potentiodynamic polarization experiments, the potential was scanned from -500 to $500 \mathrm{mV}$ at a scanning rate of $50 \mathrm{mV} \cdot \mathrm{s}^{-1}$. The corrosion current $\left(I_{\text {corr, }}\left[\mu \mathrm{A} \cdot \mathrm{cm}^{-2}\right]\right)$ was determined by superimposing a straight line along the linear portion of cathodic or anodic curve and extrapolating it through $E_{\text {corr. }}$ 
Electrochemical impedance spectroscopy (EIS) measurements in the $3.5 \% \mathrm{NaCl}$ aqueous solution were obtained by using an AutoLab (PGSTAT302N) potentiostat/galvanostat electrochemical analyzer. Impedance measurements were carried out in the frequency range of $10 \mathrm{~Hz}$ to $100 \mathrm{mHz}$ with the working electrode embedded in epoxy, a carbon rod as the counter electrode, and the saturated calomel electrode (SCE) as the reference electrode. The working electrode was kept in the test environment for $40 \mathrm{~min}$ before measurement of impedance. All experiments were performed at $25^{\circ} \mathrm{C}$. Raw data were collected at least three times to ensure reproducibility and statistical significance.

\section{Results and discussion}

\subsection{Characterization of ACAT}

The representative ${ }^{1} \mathrm{H}-\mathrm{NMR}$, Mass, and FTIR spectra for as-prepared ACAT were shown in Figure 1. From Figure 1a, the ${ }^{1} \mathrm{H}-\mathrm{NMR}$ at $\delta=5.45 \mathrm{ppm}$ and at $\delta=7.25$ to $6.50 \mathrm{ppm}$ could be assigned to the primary amine protons $\left(-\mathrm{NH}_{2}\right)$ and the splitting of the aromatic proton of ACAT, respectively. In the mass spectrum in Figure 1b, the molecular ion peak of ACAT appears at the position of 289 , which is consistent with the theoretical molecular weight of ACAT. In Figure 1c, the FTIR spectrum of ACAT showed characteristic absorption bands at 3307 and $3210 \mathrm{~cm}^{-1}$, which are due to the terminal $\mathrm{NH}_{2}$ of ACAT. Moreover, the characteristic absorption bands appearing at 1598 and $1498 \mathrm{~cm}^{-1}$ can be assigned to the vibrational bands of the quinoid ring and the benzenoid ring of ACAT, respectively.

The as-prepared ACAT was reacted with dianhydride in DMAc to yield a solution of EPAA, which was used to prepare the biomimetic EPI coating. The process for preparing biomimetic EPI coatings via the nanocasting technique is illustrated in Figure 2.

\subsection{Characterization of EPI derived from EPAA}

Figure 3 illustrates the FTIR spectra of EPAA and EPI. In Figure 3a, the EPAA exhibits its characteristic peak at $3400-3600 \mathrm{~cm}^{-1}$, which corresponds to the hydroxyl group from the carboxylic acid of EPAA. Moreover, the characteristic peak found at $3340 \mathrm{~cm}^{-1}$ can be attributed to the $\mathrm{N}-\mathrm{H}$ stretching modes. In addition, the characteristic absorption peaks found at 1596 and $1503 \mathrm{~cm}^{-1}$ were assigned to the stretching modes of $\mathrm{N}=\mathrm{Q}=\mathrm{N}$ and $\mathrm{N}-\mathrm{B}-\mathrm{N}$, respectively, where
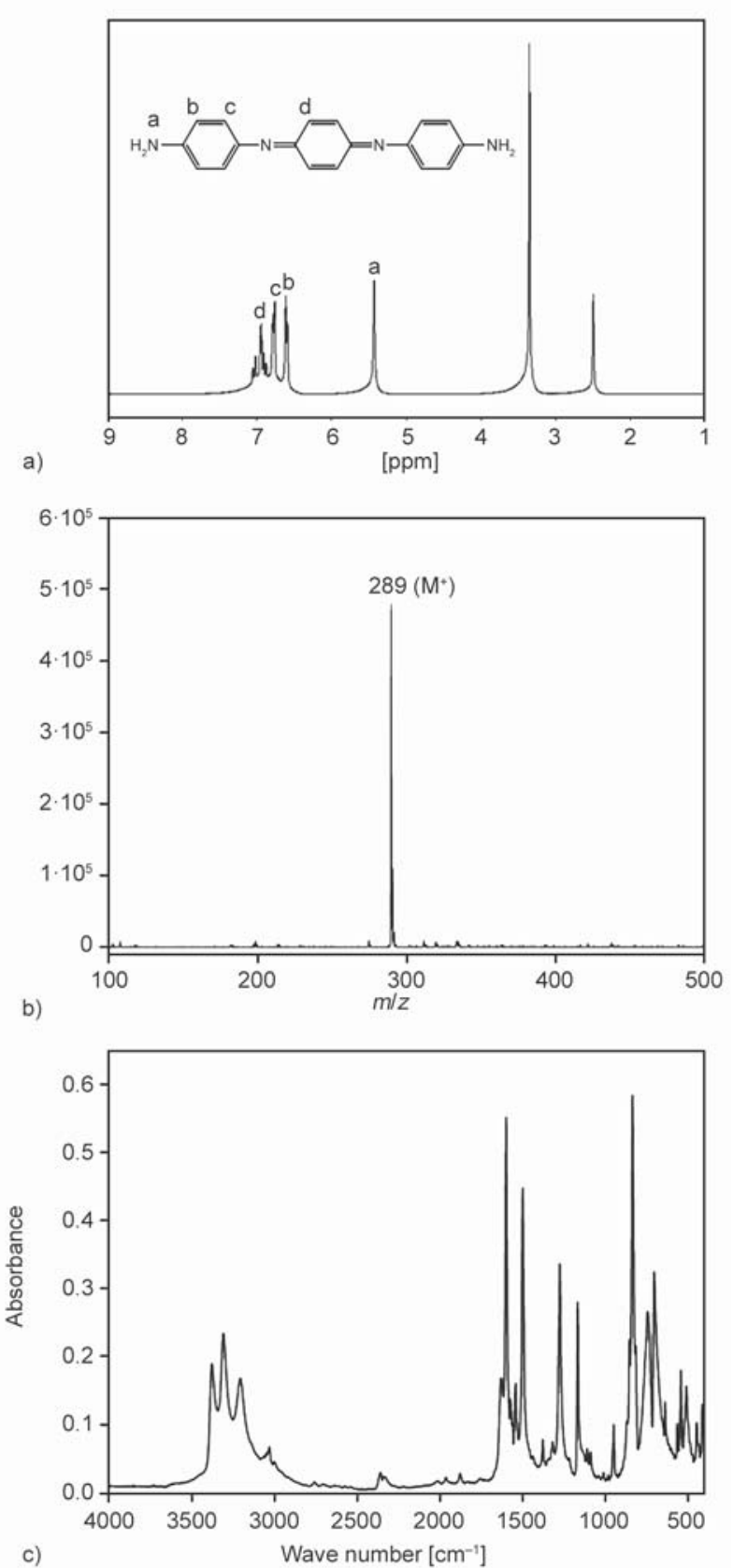

Figure 1. Characterization of as-prepared ACAT by (a) ${ }^{1} \mathrm{H}-$ NMR, (b) mass and (c) FTIR spectroscopy

$Q$ correspond to the quinoid ring and $B$ signifies the benzene ring. The characteristic peak found at $1365 \mathrm{~cm}^{-1}$ was assigned to $\mathrm{C}=\mathrm{N}$ stretching. In Figure $3 \mathrm{~b}$, the FTIR spectrum of EPI revealed a characteristic absorption band at $742 \mathrm{~cm}^{-1}$, which corresponds to the deformation of the imide group [39].

\subsection{Surface morphological studies}

Macroscopic and microscopic studies on the surface morphology of natural rose petal coatings and artificial biomimetic coatings were investigated using photography SEM, and AFM. Figure 4a shows a 


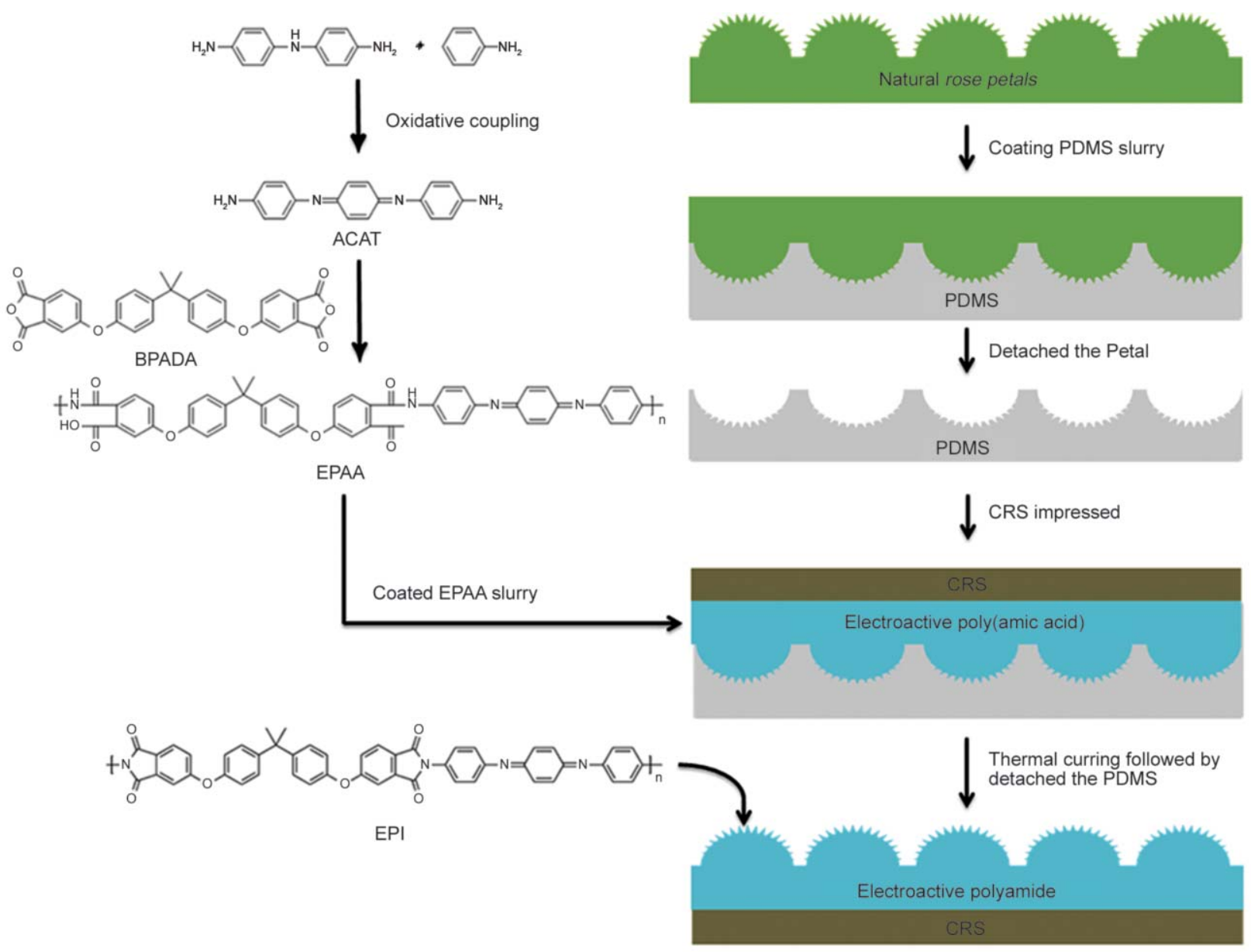

Figure 2. Flow chart for the preparation of EPI coating with biomimetic rose petal-like surface structure

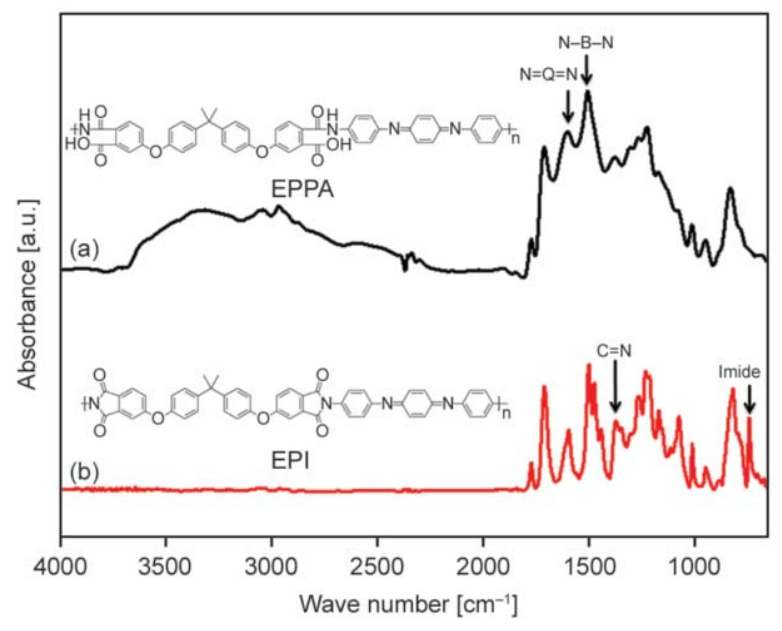

Figure 3. Representative FTIR spectra for (a) EPAA and (b) EPI

macroscopic photograph of the natural rose petal. Figures $4 \mathrm{~b}$ and $4 \mathrm{c}$ show $1000 \times$ magnification SEM micrographs of the natural fresh rose petal and artificial biomimetic rose petal-like coating, respectively. In Figure 4b, the surface morphology of the natural rose petal exhibits a hierarchical surface with a microscale hemispherical-like morphology decorated with many nanoscale wrinkles on the surface. The surface morphology of the biomimetic EPI coating appears to nearly identical to that of the natural rose petal, as shown in Figure 4c. Moreover, the threedimensional morphological surface of the biomimetic EPI coating on the CRS electrode as shown in Figure $4 \mathrm{~d}$.

\subsection{Contact angle (CA) measurements of as-prepared EPI coatings}

The contact angle of water droplets (CAWD) on two different morphologies of coatings are illustrated in Figure 5. As shown in Figure 5a, the CAWD for natural rose petal was given to be $126^{\circ}$ because of its natural micro/nano-structure. Additionally, the CAWD of PDMS template with negative micro/nano-structure was found to be $113^{\circ}$, as shown in Figure $5 \mathrm{~b}$. In Figure $5 \mathrm{c}$, the CAWD for EPI with smooth surface was found to be $87^{\circ}$. After the nanocasting treatment was employed, the CAWD of EPI with biomimetic rose petal-like surface structure which was found to be $150^{\circ}$ this structure could easily trap air within the valleys between hills, like lotus effect. As shown in 


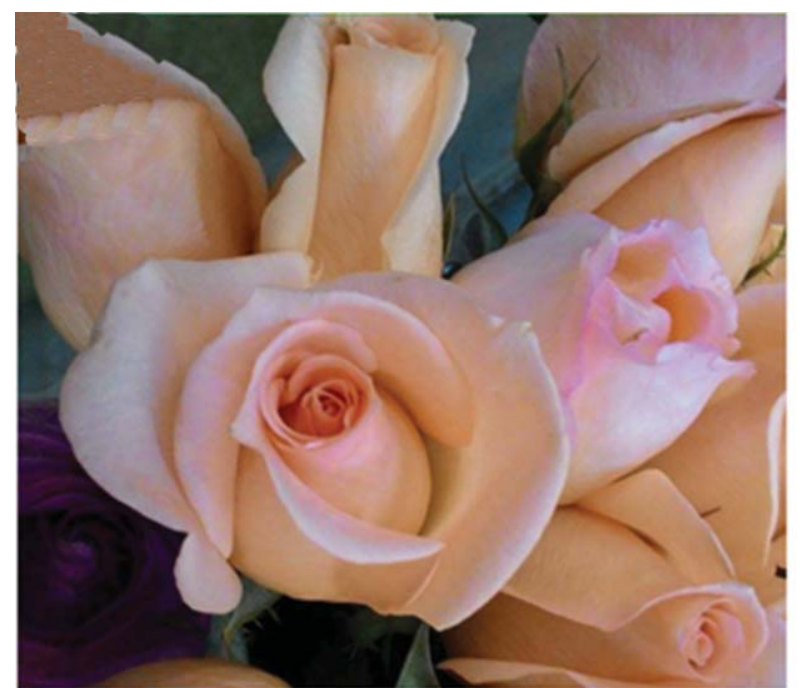

a)

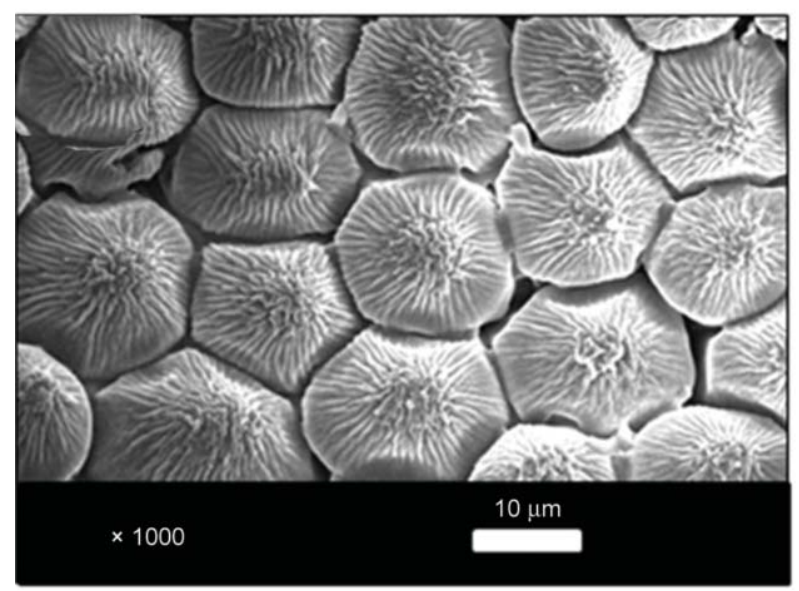

c)

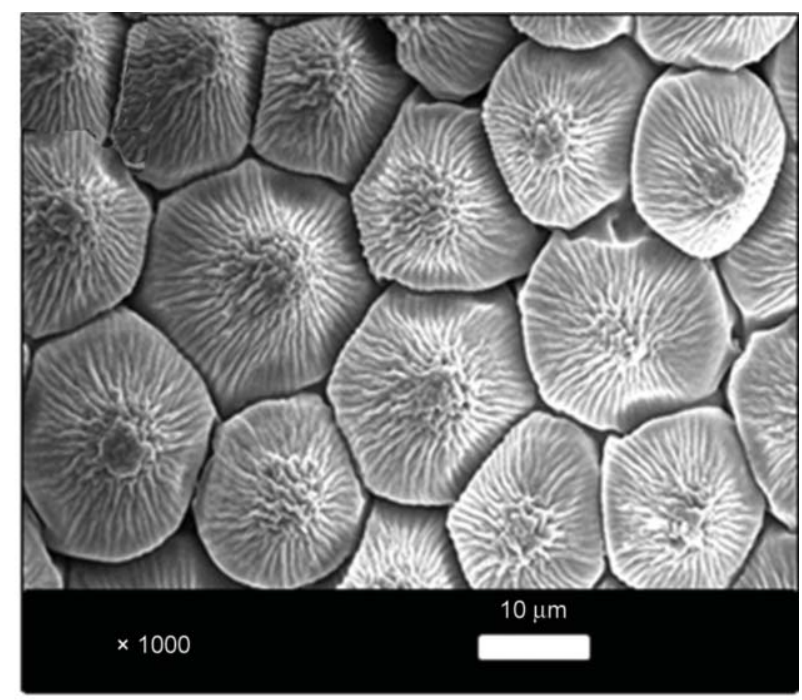

b)

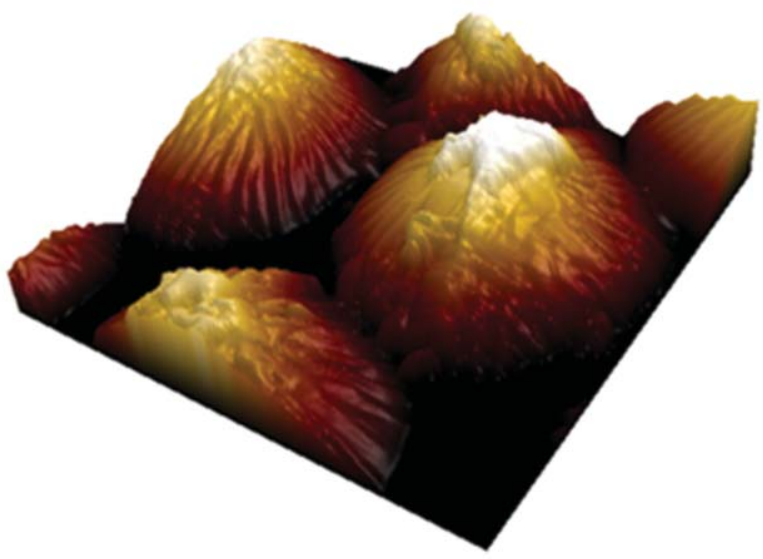

Figure 4. Macroscopic photography of the (a) natural rose petal. Microscopic SEM overlook image at magnification of $\times 1000$ for the (b) fresh natural rose petal, (c) EPI coating with biomimetic rose petal-like surface structure and (d) AFM image of EPI coating with biomimetic rose petal-like surface structure.

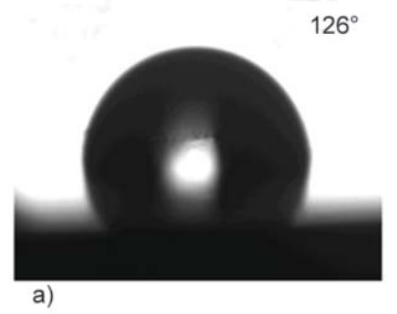

$87^{\circ}$

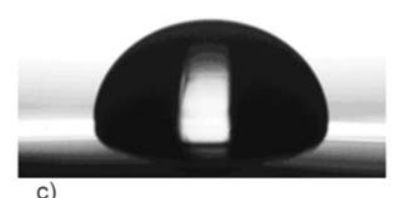

c) $113^{\circ}$

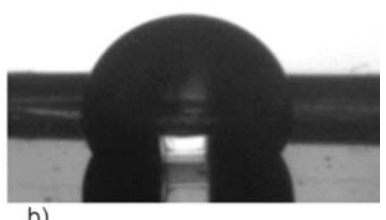

b)

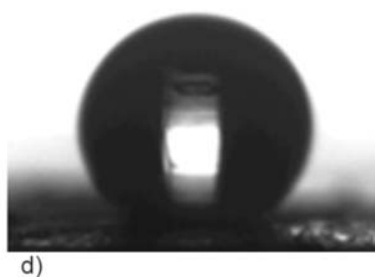

d)

Figure 5. Contact angle of water droplets for (a) natural rose petal (b) negative PDMS template (c) CRS coated by EPI and (d) CRS coated by EPI with biomimetic rose petal-like surface structure

Figure 5d, EPI with biomimetic rose petal-like surface structure was found to show an increase of $63^{\circ}$ over the standard EPI coating. Superhydrophobicity (i.e., CAWD $\sim 150^{\circ}$ ) of the biomimetic EPI implied that this biomimetic coating is a good candidate for corrosion protection.

\subsection{Electoractivity investigation of EPI coating by cyclic voltammetry}

Electroactivity of as-prepared EPI can be identified by electrochemical cyclic voltammetry. In Figure 6 , these voltammetric studies of EPI demonstrate that the coating exhibits a single oxidation peak, which is similar to many longer oligomers that undergo a twoelectron transfer [40]. The EPI coating exhibits an oxidation current $\left(I_{\mathrm{ox}}\right)$ of $0.372 \mathrm{~mA} / \mathrm{cm}^{2}$ and a reduction current $\left(I_{\mathrm{red}}\right)$ of $0.391 \mathrm{~mA} / \mathrm{cm}^{2}$. The electroactivity of EPI coatings may lead to the formation of a dense, 


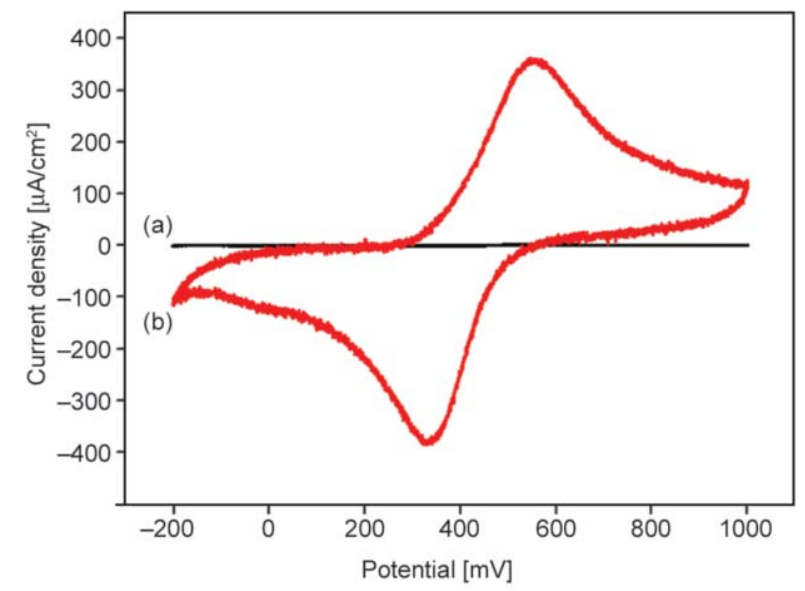

Figure 6. Cyclic voltammetry for (a) PI and (b) EPI as measured in $1.0 \mathrm{M} \mathrm{H}_{2} \mathrm{SO}_{4}$ aqueous solution with scan rate of $50 \mathrm{mV} / \mathrm{s}$

passive metal oxide layer, which would make EPI suitable for anticorrosion coating applications.

In summary, both the superhydrophobicity and electroactivity results suggest that the biomimetic rose petal-like structures of EPI coatings make them promising as anticorrosion coatings. Standard electrochemical corrosion measurements of biomimetic coating will be discussed in the follow section.

\subsection{Potentiodynamic measurement}

In this study, a series of electrochemical corrosion measurements of as-prepared coatings were carried out on CRS electrodes with electrodes with various coatings. The coated CRS electrodes were immersed in an electrolyte of $3.5 \mathrm{wt} \% \mathrm{NaCl}$ aqueous solution. Figure 7, shows the Tafel plots for the curve a) CRS coupon and curve b) CRS coated with PI, curve c)

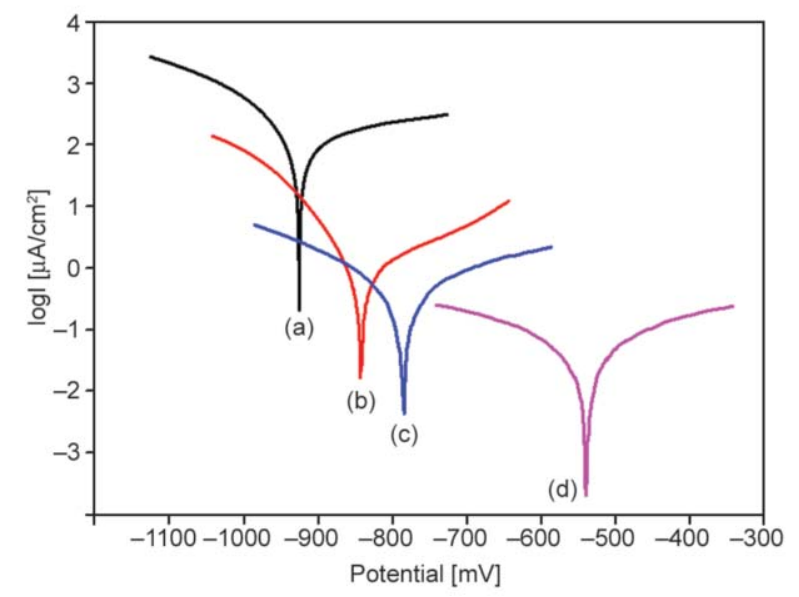

Figure 7. Tafel plots for (a) neat CRS electrode, CRS coated with (b) PI, (c) EPI and (d) EPI with biomimetic rose petal-like surface structure, as measured in $3.5 \mathrm{wt} \% \mathrm{NaCl}$ aqueous solution
Table 1. Contact angle and electrochemical corrosion measurements ${ }^{\mathrm{a}}$ of CRS, CRS coated by PI, EPI and EPI with biomimetic rose petal-like surface

\begin{tabular}{|l|c|c|c|}
\hline Sample code & $\begin{array}{c}\boldsymbol{E}_{\text {corr }} \\
{[\mathbf{m V}]}\end{array}$ & $\begin{array}{c}\boldsymbol{I}_{\text {corr }} \\
{\left[\boldsymbol{\mu} \mathbf{A} / \mathbf{c m}^{2}\right]}\end{array}$ & $\begin{array}{c}\text { Thickness } \\
{[\boldsymbol{\mu m}]}\end{array}$ \\
\hline CRS & -926 & 394.40 & - \\
\hline PI & -843 & 0.76 & $21 \pm 1$ \\
\hline EPI & -786 & 0.46 & $21 \pm 1$ \\
\hline REPI $^{*}$ & -540 & 0.05 & $21 \pm 1$ \\
\hline
\end{tabular}

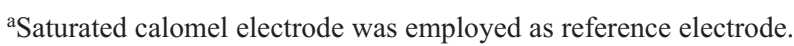
*REPI is an abbreviation for EPI with biomimetic surface structure.

EPI and curve d) EPI with biomimetic rose petallike structures. The corresponding data from Figure 7 are summarized in Table 1. Tafel plots of CRS electrodes coated with the three samples indicate that the corrosion potential $\left(E_{\text {corr }}\right)$ is more positive for the coated CRS electrodes than for the uncoated CRS electrodes. It should be noted that the corrosion potential of CRS electrodes with the biomimetic EPI coating $\left(E_{\text {corr }}=-540 \mathrm{mV}\right)$ was found to be more positive than that of electrodes with EPI $\left(E_{\text {corr }}=-\right.$ $786 \mathrm{mV}$ ) and PI coatings $\left(E_{\text {corr }}=-843 \mathrm{mV}\right)$. On the other hand, the corrosion current $\left(I_{\text {corr }}\right)$ of all coated CRS electrode is lower than that of the uncoated CRS electrode. Moreover, the corrosion current of the biomimetic EPI-coated CRS electrode $\left(I_{\text {corr }}=\right.$ $0.05 \mu \mathrm{A} / \mathrm{cm}^{2}$ ) was found to be lower than that of the electrodes with EPI $\left(I_{\text {corr }}=0.46 \mu \mathrm{A} / \mathrm{cm}^{2}\right)$ and PI coatings $\left(I_{\text {corr }}=0.76 \mu \mathrm{A} / \mathrm{cm}^{2}\right)$.

Based on the $E_{\text {corr }}$ and $I_{\text {corr }}$ data obtained from Tafel plots, the biomimetic EPI with rose petal-like surface structure was found to show better corrosion protection on the CRS electrode than PI, which may be attributed to two possible mechanisms. First, the biomimetic EPI coating with the rose petal-like surface structure has better hydrophobic characteristics than the PI coating. Secondly, the biomimetic EPI coating may form a dense, passive layer of metal oxide that that protects the steel underneath [41], which is consistent with the redox electro-catalytic results of EPI. To further investigate anticorrosion properties of these materials, the electrochemical impedance spectroscopy (EIS) results of these materials will be discussed in the following section.

\subsection{Electrochemical impedance measurements (EIS)}

EIS was used to evaluate the difference in the activity between the surface of the bare CRS electrode and the sample-coated ones. Impedance is a totally 


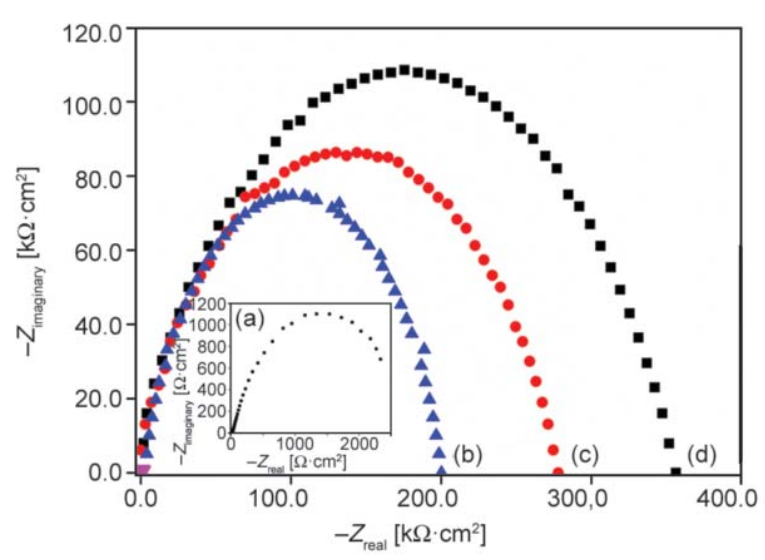

Figure 8. Nyquist plots for (a) neat CRS electrode and CRS coated with (b) PI, (c) EPI and (d) EPI with biomimetic rose petal-like surface structure as measured in $3.5 \mathrm{wt} \% \mathrm{NaCl}$ aqueous solution

complex resistance when a current flows through a circuit consisting of capacitors, resistors, or insulators, and combination thereof. Figure 8 illustrates the Nyquist plots of the four measured samples: the curve a) CRS coupon and curve b) CRS coated with PI, curve c) EPI, and curve d) EPI with a biomimetic rose petal-like surface structure. Charge transfer resistances of all samples were determined by subtracting the intersection value of the high-frequency end from that of the low-frequency end of the semicircle arc with the real axis. Results were found to be 2.3, 200.1, 277.9 and $356.2 \mathrm{k} \Omega \cdot \mathrm{cm}^{2}$ for Figure 8 curves a)-d), respectively. Moreover, Bode plots (impedance vs. frequency) of all samples are shown in Figure 9. The real impedance, or $Z_{\text {real }}$, is used to evaluate corrosion protection of the coatings. A low $Z_{\text {real }}$ value could result from a very high capacitance

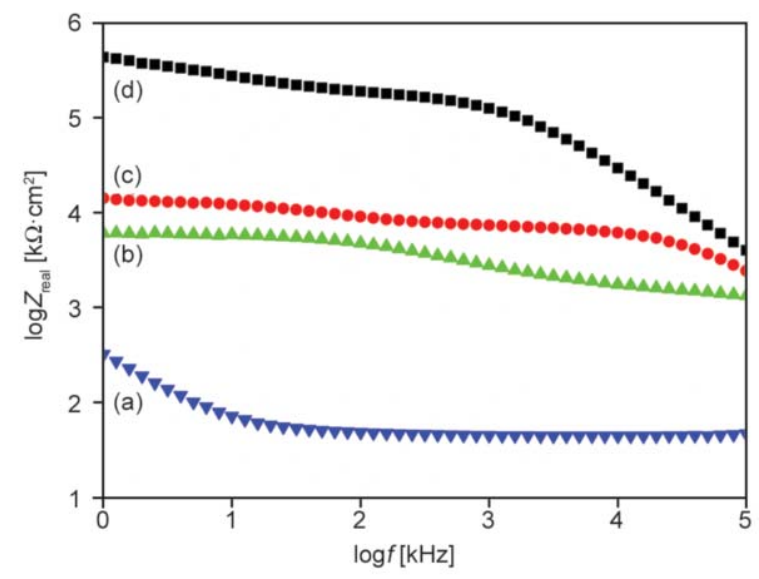

Figure 9. Bode plots for (a) neat CRS electrode and CRS coated with (b) PI, (c) EPI and (d) EPI with biomimetic rose petal-like surface structure as measured in $3.5 \mathrm{wt} \% \mathrm{NaCl}$ aqueous solution and/or very low resistance of the coating. In the case of Bode plots, the value of $Z_{\text {real }}$ at the lowest frequency also represents corrosion protection. The Bode plots for bare CRS and CRS coated with PI, EPI, and EPI with biomimetic rose petal-like surface structures show Zreal values of 2.5, 3.7, 4.2 and $5.6 \mathrm{k} \Omega \cdot \mathrm{cm}^{2}$, respectively, at the low frequency end. Note that the result obtained from the EIS (Nyquist plots and Bode plots) is consistent with the previous conclusion based on the Tafel plots.

\section{Conclusions}

EPI coatings with rose petal-like surface structures are prepared and investigated for their potential application as anticorrosion coatings. The EPI coatings with rose petal-like surface structures were compared to both EPI and PI without the biomimetic structure. To produce these EPI coatings, ACAT was successfully synthesized by an oxidative coupling reaction, and characterized with FTIR and ${ }^{1} \mathrm{H}-\mathrm{NMR}$ spectroscopy and LC-Mass spectrometry. The characterized ACAT was reacted with BPADA in a DMAc solution to produce EPAA, which was eventually cured to form EPI. A nanocasting technique was used to produce a PDMS soft negative template suitable for pattern transfer by using natural rose petals as the template, leading to the formation of a biomimetic EPI coating. Investigation of the surface morphology of as-prepared biomimetic EPI via SEM and AFM revealed a natural rose petal-like hierarchical surface with a microscale hemispherical-like morphology decorated with many nanoscale wrinkles on the top surface. This morphology affects the hydrophobicity of the material. The surface contact angle of water droplets for the biomimetic EPI coating was found to be $\sim 150^{\circ}$, which was significantly higher than that of smooth EPI $\left(\sim 87^{\circ}\right)$, indicating that the coating with the biomimetic structures effectively repels water droplets. Finally, the electroactivity of biomimetic EPI coatings was evaluated using electrochemical cyclic voltammetry, potentiodynamic measurement techniques, and electrochemical impedance measurements. Biomimetic EPI was compared to both EPI and PI without a biomimetic surface structure. In each measurement of the electroactivity of biomimetic EPI, the results indicated an improvement in corrosion resistance compared to EPI and PI without the biomimetic structures, as a result of the formation of a dense, passive layer of metal oxide on the surface of the metal. 


\section{Acknowledgements}

The authors acknowledge financial support from the Ministry of Science and Technology, Taiwan, R.O.C. (NSC 102-2632M-033-001-MY3) and (MOST 104-2113-M-033-001-MY3); the Department of Chemistry at CYCU; the Center for Nanotechnology and Center for Biomedical Technology at CYCU.

\section{References}

[1] Xia F., Jiang L.: Bio-inspired, smart, multiscale interfacial materials. Advanced Materials, 20, 2842-2858 (2008).

https://doi.org/10.1002/adma.200800836

[2] Bhushan B., Jung Y. C.: Natural and biomimetic artificial surfaces for superhydrophobicity, self-cleaning, low adhesion, and drag reduction. Progress in Materials Science, 56, 1-108 (2011). https://doi.org/10.1016/j.pmatsci.2010.04.003

[3] Liu K., Jiang L.: Multifunctional integration: From biological to bio-inspired materials. ACS Nano, 5, 67866790 (2011). https://doi.org/10.1021/nn203250y

[4] Tao X., Li Y., Du J., Xia Y., Yang Y., Huang H., Gan Y., Zhang W., Li X.: A generic bamboo-based carbothermal method for preparing carbide ( $\mathrm{SiC}, \mathrm{B}_{4} \mathrm{C}, \mathrm{TiC}, \mathrm{TaC}, \mathrm{NbC}$, $\mathrm{Ti}_{\mathrm{x}} \mathrm{Nb}_{1-\mathrm{x}} \mathrm{C}$, and $\mathrm{Ta}_{\mathrm{x}} \mathrm{Nb}_{1-\mathrm{x}} \mathrm{C}$ ) nanowires. Journal of Materials Chemistry, 21, 9095-9102 (2011).

https://doi.org/10.1039/c1jm10730e

[5] Zampieri A., Sieber H., Selvam T., Mabande G. T. P., Schwieger W., Scheffler F., Scheffler M., Greil P.: Biomorphic cellular SiSiC/zeolite ceramic composites: From rattan palm to bioinspired structured monoliths for catalysis and sorption. Advanced Materials, 17, 344-349 (2005).

https://doi.org/10.1002/adma.200400672

[6] Raymundo-Piñero E., Cadek M., Béguin F.: Tuning carbon materials for supercapacitors by direct pyrolysis of seaweeds. Advanced Functional Materials, 19, 10321039 (2009).

https://doi.org/10.1002/adfm.200801057

[7] Biswal M., Banerjee A., Deo M., Ogale S.: From dead leaves to high energy density supercapacitors. Energy and Environmental Science, 6, 1249-1259 (2013). https://doi.org/10.1039/c3ee22325f

[8] Weng C-J., Chang C-H., Peng C-W., Chen S-W., Yeh J-M., Hsu C-L., Wei Y.: Advanced anticorrosive coatings prepared from the mimicked xanthosoma sagittifolium-leaf-like electroactive epoxy with synergistic effects of superhydrophobicity and redox catalytic capability. Chemistry of Materials, 23, 2075-2083 (2011). https://doi.org/10.1021/cm1030377

[9] Schnepp Z., Yang W., Antonietti M., Giordano C.: Biotemplating of metal carbide microstructures: The magnetic leaf. Angewandte Chemie International Edition, 49, 6564-6566 (2010).

https://doi.org/10.1002/anie.201001626
[10] Balathanigaimani M. S., Shim W-G., Lee M-J., Kim C., Lee J-W., Moon H.: Highly porous electrodes from novel corn grains-based activated carbons for electrical double layer capacitors. Electrochemistry Communications, 10, 868-871 (2008).

https://doi.org/10.1016/j.elecom.2008.04.003

[11] Ding J., Wang H., Li Z., Cui K., Karpuzov D., Tan X., Kohandehghan A., Mitlin D.: Peanut shell hybrid sodium ion capacitor with extreme energy-power rivals lithium ion capacitors. Energy and Environmental Science, 8, 941-955 (2015).

https://doi.org/10.1039/c4ee02986k

[12] Rufford T. E., Hulicova-Jurcakova D., Khosla K., Zhu Z., Lu G. Q.: Microstructure and electrochemical double-layer capacitance of carbon electrodes prepared by zinc chloride activation of sugar cane bagasse. Journal of Power Sources, 195, 912-918 (2010). https://doi.org/10.1016/j.jpowsour.2009.08.048

[13] Tao X., Dong L., Wang X., Zhang W., Nelson B. J., Li $\mathrm{X} .: \mathrm{B}{ }_{4} \mathrm{C}$-nanowires/carbon-microfiber hybrid structures and composites from cotton T-shirts. Advance Materials, 22, 2055-2059 (2010). https://doi.org/10.1002/adma.200903071

[14] Liu H-J., Wang X-M., Cui W-J., Dou Y-Q., Zhao D-Y., Xia Y-Y.: Highly ordered mesoporous carbon nanofiber arrays from a crab shell biological template and its application in supercapacitors and fuel cells. Journal of Materials Chemistry, 20, 4223-4230 (2010).

https://doi.org/10.1039/b925776d

[15] Huang J., Wang X., Wang Z. L.: Controlled replication of butterfly wings for achieving tunable photonic properties. Nano Letters, 6, 2325-2331 (2006).

https://doi.org/10.1021/n1061851t

[16] Jeffryes C., Campbell J., Li H., Jiao J., Rorrer G.: The potential of diatom nanobiotechnology for applications in solar cells, batteries, and electroluminescent devices. Energy and Environmental Science, 4, 3930-3941 (2011). https://doi.org/10.1039/c0ee00306a

[17] Li Z., Zhang L., Amirkhiz B. S., Tan X., Xu Z., Wang H., Olsen B. C., Holt C. M. B., Mitlin D.: Carbonized chicken eggshell membranes with $3 \mathrm{D}$ architectures as high-performance electrode materials for supercapacitors. Advanced Energy Materials, 2, 431-437 (2012). https://doi.org/10.1002/aenm.201100548

[18] Xia Y., Zhang W., Xiao Z., Huang H., Zeng H., Chen X., Chen F., Gan Y., Tao X.: Biotemplated fabrication of hierarchically porous $\mathrm{NiO} / \mathrm{C}$ composite from lotus pollen grains for lithium-ion batteries. Journal of Materials Chemistry, 22, 9209-9215 (2012). https://doi.org/10.1039/c2jm16935e

[19] Zhao Y., Wei M., Lu J., Wang Z. L., Duan X.: Biotemplated hierarchical nanostructure of layered double hydroxides with improved photocatalysis performance. ACS Nano, 3, 4009-4016 (2009). https://doi.org/10.1021/nn901055d

[20] Sun H., Cao L., Lu L.: Bacteria promoted hierarchical carbon materials for high-performance supercapacitor. Energy and Environmental Science, 5, 6206-6213 (2012). https://doi.org/10.1039/c2ee 03407g 
[21] Shim H-W., Lim A-H., Min K-M., Kim D-W.: Synthesis of manganese oxide nanostructures using bacterial soft templates. CrystEngComm, 13, 6747-6752 (2011). https://doi.org/10.1039/c1ce05619k

[22] Zhou H., Fan T., Zhang D., Guo Q., Ogawa H.: Novel bacteria-templated sonochemical route for the in situ one-step synthesis of $\mathrm{ZnS}$ hollow nanostructures. Chemistry of Materials, 19, 2144-2146 (2007). https://doi.org/10.1021/cm0629311

[23] Lee Y. J., Yi H., Kim W-J., Kang K., Yun D. S., Strano M. S., Ceder G., Belcher A. M.: Fabricating genetically engineered high-power lithium-ion batteries using multiple virus genes. Science, 324, 1051-1055 (2009). https://doi.org/10.1126/science.1171541

[24] Yuan L., Yao B., Hu B., Huo K., Chen W., Zhou J.: Polypyrrole-coated paper for flexible solid-state energy storage. Energy and Environmental Science, 6, 470-476 (2013). https://doi.org/10.1039/c2ee23977a

[25] Wang H., Bian L., Zhou P., Tang J., Tang W.: Core-sheath structured bacterial cellulose/polypyrrole nanocomposites with excellent conductivity as supercapacitors. Journal of Materials Chemistry A, 1, 578-584 (2013). https://doi.org/10.1039/c2ta00040g

[26] Kang Y. J., Chun S-J., Lee S-S., Kim B-Y., Kim J. H., Chung H., Lee S-Y., Kim W.: All-solid-state flexible supercapacitors fabricated with bacterial nanocellulose papers, carbon nanotubes, and triblock-copolymer ion gels. ACS Nano, 6, 6400-6406 (2012).

https://doi.org/10.1021/nn301971r

[27] Liu L., Niu Z., Zhang L., Zhou W., Chen X., Xie S.: Nanostructured graphene composite papers for highly flexible and foldable supercapacitors. Advanced Materials, 26, 4855-4862 (2014). https://doi.org/10.1002/adma.201401513

[28] Li S., Huang D., Zhang B., Xu X., Wang M., Yang G., Shen Y.: Flexible supercapacitors based on bacterial cellulose paper electrodes. Advanced Energy Materials, 4, 1301655/1-1301655/7 (2014). https://doi.org/10.1002/aenm.201301655

[29] Razaq A., Nyholm L., Sjödin M., Strømme M., Mihranyan A.: Paper-based energy-storage devices comprising carbon fiber-reinforced polypyrrole-cladophora nanocellulose composite electrodes. Advanced Energy Materials, 2, 445-454 (2012).

https://doi.org/10.1002/aenm.201100713

[30] Sokolov A. N., Yap F. L., Liu N., Kim K., Ci L., Johnson O. B., Wang H., Vosgueritchian M., Koh A. L., Chen J., Park J., Bao Z.: Direct growth of aligned graphitic nanoribbons from a DNA template by chemical vapour deposition. Nature Communications, 4, 2402/1-2402/8 (2013).

https://doi.org/10.1038/ncomms3402

[31] De Flora S., Bagnasco M., Serra D., Zanacchi P.: Genotoxicity of chromium compounds. A review. Mutation Research/Reviews in Genetic Toxicology, 238, 99-172 (1990).

https://doi.org/10.1016/0165-1110(90)90007-X
[32] Cohen M. D., Kargacin B., Klein C. B., Costa M.: Mechanisms of chromium carcinogenicity and toxicity. Critical Reviews in Toxicology, 23, 255-281 (1993). https://doi.org/10.3109/10408449309105012

[33] Wessling B.: Passivation of metals by coating with polyaniline: Corrosion potential shift and morphological changes. Advanced Materials, 6, 226-228 (1994). https://doi.org/10.1002/adma.19940060309

[34] Weng C-J., Huang J-Y., Huang K-Y., Jhuo Y-S., Tsai M-H., Yeh J-M.: Advanced anticorrosive coatings prepared from electroactive polyimide- $\mathrm{TiO}_{2}$ hybrid nanocomposite materials. Electrochimica Acta, 55, 84308438 (2010). https://doi.org/10.1016/j.electacta.2010.07.063

[35] Huang K-Y., Shiu C-L., Wu P-S., Wei Y., Yeh J-M., Li W-T.: Effect of amino-capped aniline trimer on corrosion protection and physical properties for electroactive epoxy thermosets. Electrochimica Acta, 54, 5400-5407 (2009).

https://doi.org/10.1016/j.electacta.2009.04.030

[36] Peng C-W., Hsu C-H., Lin K-H., Li P-L., Hsieh M-F., Wei Y., Yeh J-M., Yu Y-H.: Electrochemical corrosion protection studies of aniline-capped aniline trimer-based electroactive polyurethane coatings. Electrochimica Acta, 58, 614-620 (2011). https://doi.org/10.1016/j.electacta.2011.10.002

[37] Chang K-C., Hsu M-H., Lu H-I., Lai M-C., Liu P-J., Hsu C-H., Ji W-F., Chuang T-L., Wei Y., Yeh J-M., Liu W-R.: Room-temperature cured hydrophobic epoxy/ graphene composites as corrosion inhibitor for coldrolled steel. Carbon, 66, 144-153 (2014). https://doi.org/10.1016/j.carbon.2013.08.052

[38] Peng C-W., Chang K-C., Weng C-J., Lai M-C., Hsu CH., Hsu S-C., Li S-Y., Wei Y., Yeh J-M.: UV-curable nanocasting technique to prepare bio-mimetic super-hydrophobic non-fluorinated polymeric surfaces for advanced anticorrosive coatings. Polymer Chemistry, 4, 926-932 (2013).

https://doi.org/10.1039/C2PY20613G

[39] Chang K-C., Lu H-I., Peng C-W., Lai M-C., Hsu S-C., Hsu M-H., Tsai Y-K., Chang C-H., Hung W-I., Wei Y., Yeh J-M.: Nanocasting technique to prepare lotus-leaflike superhydrophobic electroactive polyimide as advanced anticorrosive coatings. ACS Applied Materials and Interfaces, 5, 1460-1467 (2013).

https://doi.org/10.1021/am3029377

[40] Weng C-J., Huang K-Y., Jhuo Y-S., Chen Y-L., Feng CF., Chien C-M., Yeh J-M.: Electroactive PI sphere generated by electrospraying. Polymer International, 61, 205-212 (2012). https://doi.org/10.1002/pi.3170

[41] Huang H-Y., Huang T-C., Yeh T-C., Tsai C-Y., Lai CL., Tsai M-H., Yeh J-M., Chou Y-C.: Advanced anticorrosive materials prepared from amine-capped aniline trimer-based electroactive polyimide-clay nanocomposite materials with synergistic effects of redox catalytic capability and gas barrier properties. Polymer, 52, 2391-2400 (2011).

https://doi.org/10.1016/j.polymer.2011.03.030 